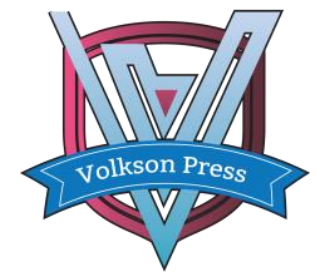

Contents List available at VOLKSON PRESS

Engineering \& Technology Innovations (ETI)

DOI : http://doi.org/10.26480/iceti.01.2017.98.100

\title{
SIMULATED BALLAST WATER TREATMENT BY ELECTROLYSIS PROCESS
}

\author{
Donghai Wu' ${ }^{*}$, Guanghua Lu', Ran Zhang ${ }^{2}$, Zhou Chao' ${ }^{1}$ Xinghou Shen ${ }^{3}$, Wei Wang ${ }^{3}$
}

${ }^{1}$ Key Laboratory of Integrated Regulation and Resource Development on Shallow Lakes of Ministry of Education, College of Environment, HohaiUniversity, Nanjing 210098, China.

${ }^{2}$ State Key Laboratory of Urban Water Resource and Environment, Harbin Institute of Technology, P.O. Box 2606, 202 Haihe Road, Harbin 150090, China.

${ }^{3}$ Henan Province Hydrology and Water Resources Bureau, Zhengzhou, 450004, China.

*Corresponding author. E-mail address: wdh1018@hhu.edu.cn

\section{ARTICLE DETAILS}

\section{Article History:}

Received 02 october 2017

Accepted 06 october 2017

Available online 11 october 2017

\section{Keywords:}

Ballast water; electrolysis; . total residual oxidant; algae; inactivation.

\section{ABSTRACT}

This work investigates the use of electrolysis for ballast water treatment. The total residual oxidant (TRO) generation and microalgae inactivation were examined, and the effects of hydraulic residence time (HRT), current density, and water salinity were evaluated. Results show that TRO could be generated by seawater electrolysis, and the produced TRO concentration was positively correct with HRT, current density, and water salinity. The increase in water salinity decreased energy consumption, while the effects of HRT and current density on energy efficiency were complex. The persistence of TRO resulted in algae inactivation in the effluent. Considering efficiency and cost, electrolysis technology has advantages in ballast water treatment.

\section{INTRODUCTION}

At Ballast water is water taken by ships to ensure their stability and maneuverability during transit [1]. However, discharge ballast water will introduce exotic organisms into local water environment, which may affect the aquatic ecosystem [2]. In the discharged ballast water, active organisms should at least meet the regulation D-2 ballast water discharge standard $[3,4]$.

Recently, sequential filtration and inactivation process has been recommended as the main technology for ballast water treatment [5]. Among various inactivation processes, ultraviolet (UV) radiation and electrolysis are two excellent technologies [6, 7]. UV radiation is a wildly used disinfection technology with high efficiency and safety. But the UV dose for plankton inactivation is much higher than bacteria [8], which means the energy consumption for ballast water treatment by UV radiation alone maybe high. Moreover, during deballasting process, secondary UV treatment is required to remove the reactivated microorganisms. In most cases, ship's ballast water is seawater, which contains huge amounts of salts. Seawater electrolysis can generate oxidants (e.g. chlorine and bromine) as disinfectants. Some reports have demonstrated the efficiency of electrolysis for ballast water treatment. However, traditional electrolysis using high current density may increase the risk of toxic byproducts formation.

In this study, electrolysis with low current density was applied for ballast water treatment. The production of total residual oxidant (TRO) during electrolysis was determined, and the effects of current density, hydraulic residence time (HRT), and salinity were investigated. The electrolysis treatment efficiency was evaluated by employing microalgae as probs.

\section{Materials and Methods}

\subsection{Artificial seawater and test culture}

Artificial seawater was prepared by adding seasalts to deionized water. Microalgae harvested from nature seawater was used as the indicator organism in this study. After enriched in Guillard's f/2 medium, cells were diluted with artificial seawater to yield a cell concentration of about $2 \times 10^{5}$ cells/mL before tests.

\subsection{Experimental set-up}

Fig. 1 illustrates the experimental setup.

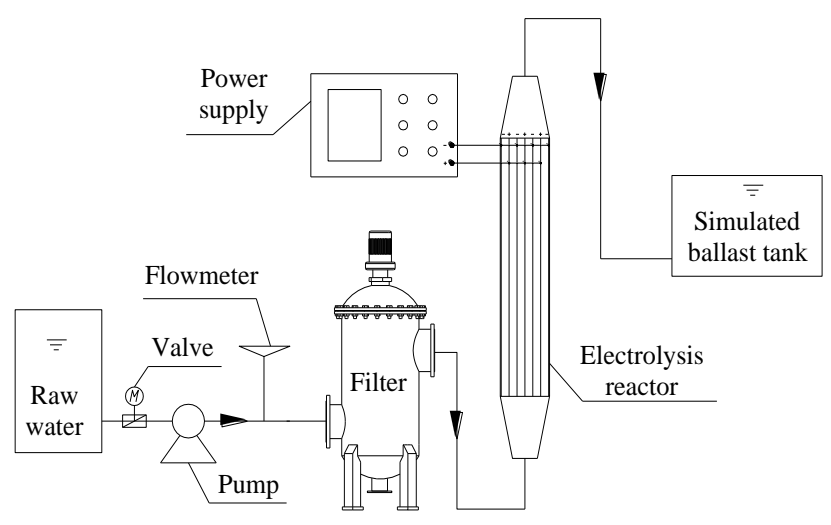

Fig. 1. Schematic diagram of experimental setup.

The simulated ballast water was firstly pumped through a $40 \mu \mathrm{m}$ sieve filter, and was then introduced into an electrolysis reactor. The electrolysis reaction area with a width of $5 \mathrm{~cm}$, depth of $8 \mathrm{~cm}$, and height of $25 \mathrm{~cm}$. Three anodes and four cathodes are installed in the reactor, with $8 \mathrm{~mm}$ between each electrode. The anode material is $\mathrm{RuO2} / \mathrm{Ti}$ and the cathodes were stainless steel. The water flow rate was $1-4 \mathrm{t} / \mathrm{h}$, corresponding with HRT of 3.46-0.86 s. The TRO produced by electrolysis was analyzed immediately, while TRO decay and the algae durability in effluent were periodically measured.

\subsection{Analysis methode}

TRO was meansured by the standard N,N-diethyl-p-phenylenediamine colorimetric analysis for total chlorine [9]. The measurement of microalgae was according to the methode described in elswhere [7]. The current and voltage were monitored by the power supply, and the electric power can be calculated by multiplying the current and voltage. 


\section{Results and discussion}

\subsection{Effect of HRT on TRO generation}

As shown in Fig. 2, electrolysis was efficient in TRO generation in seawater, and the effluent TRO concentration increased with the increasing of HRT. For instance, the detected TRO for HRT 0.86 and $3.46 \mathrm{~s}$ were 0.7 and 2.7 $\mathrm{mg} / \mathrm{L}$. Both bromine and chlorine can be produced by electrolysis in seawater. Although the concentration of $\mathrm{Cl}^{-}$is much higher than that of $\mathrm{Br}^{-}$ in seawater, Jung et al. indicated that the formed chlorine could quickly change into bromine during seawater electrolysis, and bromine was the main component of the measured TRO [10].

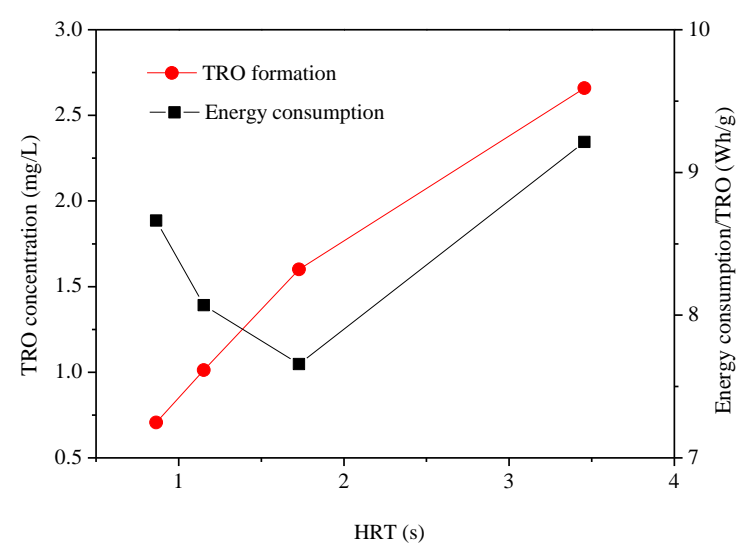

Fig. 2 Effects of HRT on TRO production and energy efficiency.

The energy consumption for per gram TRO production was calculated, and the results were also shown in Fig. 2. Increasing HRT to a specific level could improve the energy efficiency, while further increase resulted in a decarese in energy efficiency. The lowest energy consumption for per gram TRO production was obtained at HRT $1.73 \mathrm{~s}$.

\subsection{Effects of current density and salinity on TRO generation}

Fig. 3 demonstrates the effects of current density and salinity on TRO production at HRT of $0.86 \mathrm{~s}$. As can be seen, the produced TRO concentration increased with increasing current density and seawater salinity. With the current density of $4 \mathrm{~mA} / \mathrm{cm}^{2}$, the produced TRO production for salinity of 22 and 34 PSU were 0.6 and $0.7 \mathrm{mg} / \mathrm{L}$. When the current density increased to $12 \mathrm{~mA} / \mathrm{cm}^{2}, 2.5$ and $3.0 \mathrm{mg} / \mathrm{L}$ TRO were obtained for 22 and 34 PSU salinity seawater electrolysis, respectively. Increasing current density increased the reaction amount of anion at anode, thereby enhancing the generation of TRO.

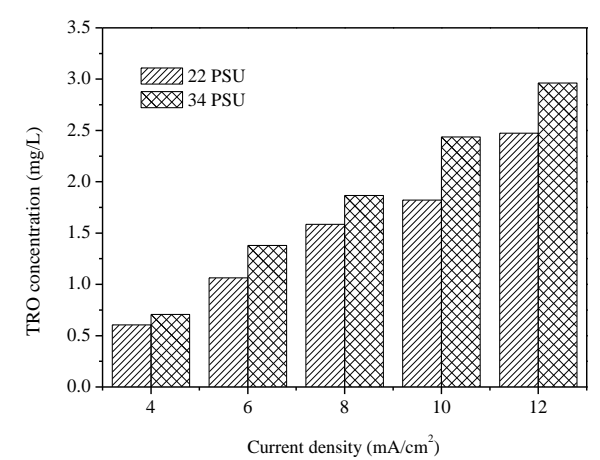

Fig. 3 Effects of current density and salinity on TRO production.

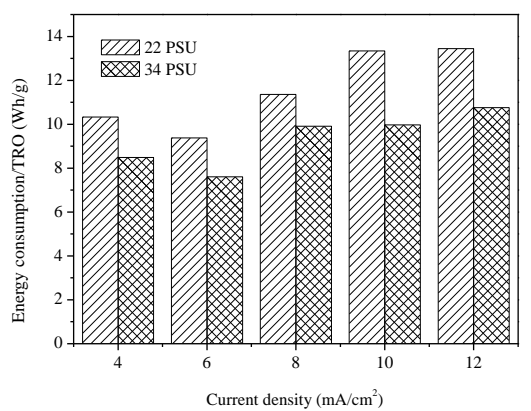

Fig. 4 Effects of current density and salinity on energy efficiency.
Fig. 4 shows the effects of current density and salinity on electrolysis treatment energy efficiency at HRT of $0.86 \mathrm{~s}$. Results suggest that the higher salinity seawater electrolysis had the higher energy efficiency. This may because the higher salinity seawater has the lower resistance, thus the energy consumption by seawater was decreased with the increasing of water salinity. On the other hand, the lowest energy consumption for per gram TRO production was obtained at current density of $6 \mathrm{~mA} / \mathrm{cm}^{2}$ in both 22 and 34 PSU salinity seawater electrolysis treatment.

\subsection{TRO decay}

Fig. 5 shows the decay of TRO in the effluent after electrolysis treatment. In all samples, TRO concentrations reduced with the stored time. With the initial TRO concentration less than $2.5 \mathrm{mg} / \mathrm{L}$, nearly no TRO could be detected after $24 \mathrm{~h}$. However, with the initial TRO of $3.4 \mathrm{mg} / \mathrm{L}$, the residual TRO was $1.3 \mathrm{mg} / \mathrm{L}$ after $24 \mathrm{~h}$. This phenomenon imply that the effluent with higher TRO provides toxicity for a longer time. No obvious difference was detected between the TRO decay in 22 and 34 PSU salinity samples.
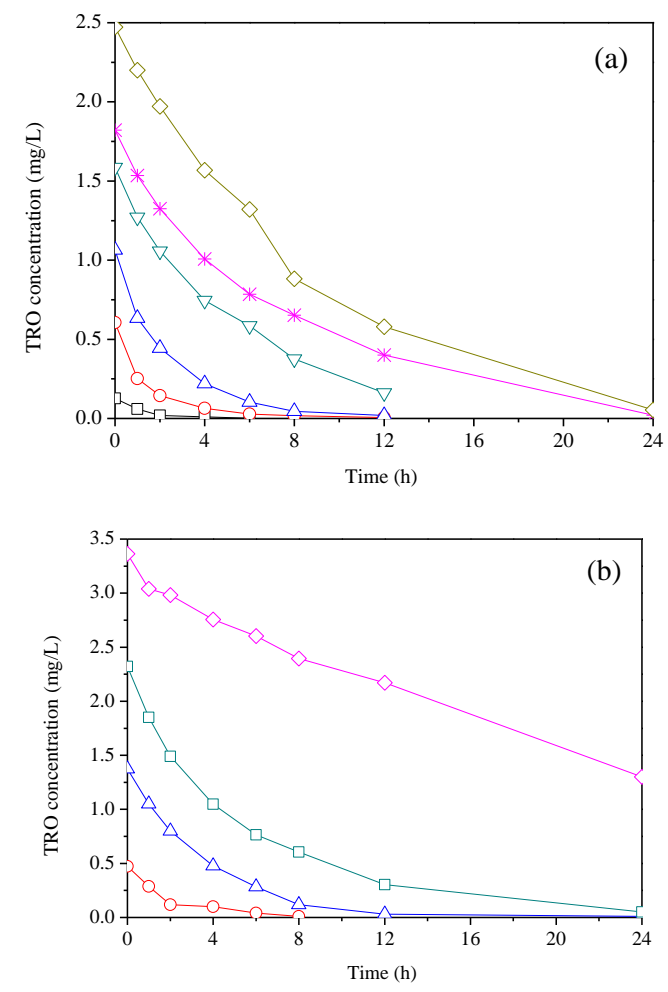

Fig. 5. Decay of TRO in the effluent with 22 PSU (a) and 34 PSU (b) salinity

\subsection{Microalgae inactivation}

After sequential filtration and electrolysis treatment, the microalgae inactivation in the effluent was evaluated. As shown in Table 1 , the microalgae durability in the effluent reduced with the increasing TRO. With the initial TRO concentration of $0.7 \mathrm{mg} / \mathrm{L}$, the microalgae in the effluent could not be inactivated completely within $6 \mathrm{~h}$. Contrastly, when the initial TRO concentration increased above $1.1 \mathrm{mg} / \mathrm{L}$, complete microalgae inactivation was achieved within $6 \mathrm{~h}$. The effects of electrolysis and produced TRO on microorganisms inactivation need further deep investigation.

Table 1 Combinations of TRO concentrations and contact times for microalgae inactivation in effluent.

\begin{tabular}{|c|c|c|c|c|c|c|}
\hline Salinity (PSU) & 22 & & & 34 & & \\
\hline $\begin{array}{ll}\text { Initial } & \text { TRO } \\
(\mathrm{mg} / \mathrm{L}) & \end{array}$ & 1.1 & 1.6 & $\begin{array}{l}0 \\
\text { (control) }\end{array}$ & 0.7 & 1.4 & 0 (control) \\
\hline Initial & $\mathrm{Y}$ & Y & Y & Y & Y & $\mathrm{Y}$ \\
\hline After $3 \mathrm{~h}$ & $\mathrm{Y}$ & Y & $\mathrm{Y}$ & $\mathrm{Y}$ & Y & Y \\
\hline After $6 \mathrm{~h}$ & $\mathrm{~N}$ & $\mathrm{~N}$ & $\mathrm{Y}$ & Y & $\mathrm{N}$ & $\mathrm{Y}$ \\
\hline
\end{tabular}

Y: active microalgae could be observed; N: none active microalgae was observed.

\section{Conclusions}

This work reveals that electrolysis was efficient for TRO generation in 
simulated ballast water. Appropriate increasing of HRT, current density, and water salinity could improve the production of TRO. Increasing water salinity reduced the energy consumption, and the influences of HRT and current density on energy efficiency were complex. It should be noted that although the high HRT and current density might decrease the energy efficiency, electrolysis treatment should produce sufficient TRO to ensure the microorganisms inactivation. Microalgae in seawater could not be inactivated immediately during electrolysis treatment, however, persistence of TRO caused a cumulative mortality in the effluent.

\section{Acknowledgements}

We are grateful for grants from the National Natural Science Foundation of China (No. 51608167), Scientific and Technological Project of Henan Province (No. 162102310057), and A Project Funded by the Priority Academic Program Development of Jiangsu Higher Education Institutions.

\section{References}

[1] Wu, D., You, H., Zhang, R., et al.. Inactivation of Escherichia coli using $\mathrm{UV} / \mathrm{Ag}-\mathrm{TiO}_{2} / \mathrm{O}_{3}$-mediated advanced oxidation: application to ballast water disinfection, J. Chem. Technol. Biotechnol., 2011, 86, pp. 1521-1526.

[2] Bai, M., Zheng, Q., Tian, Y., et .. Inactivation al of invasive marine species in the process of conveying ballast water using $\mathrm{OH}$ based on a strong ionization discharge, Water Res., 2016, 96, pp. 217-224.
[3] Gollasch, S., David, M., Voigt, M., et al.. Critical review of the IMO international convention on the management of ships' ballast water and sediments, Harmful Algae, 2007, 6, pp. 585-600.

[4] Chen, S., Hu, W., Hong, J., et al.. Electrochemical disinfection of simulated ballast water on PbO2/graphite felt electrode, Mar. Pollut. Bull., 2016, 105, pp. 319-323.

[5] Bakalar, G.. Comparisons of interdisciplinary ballast water treatment systems and operational experiences from ships, Springer Plus, 2016, 5 , pp. 12.

[6] Liu, L., Chu, X.N., Chen, P.Y., et al.. Effects of water quality on inactivation and repair of Microcystis viridis and Tetraselmis suecica following medium-pressure UV irradiation, Chemosphere, 2016, 163, pp. 209-216.

[7] Lacasa, E., Tsolaki, E., Sbokou, Z., et al.. Electrochemical disinfection of simulated ballast water on conductive diamond electrodes, Chem. Eng. J., 2013, 223, pp. 516-523.

[8] Tsolaki, E., Diamadopoulos, E.. Technologies for ballast water treatment: a review, J. Chem. Technol. Biotechnol., 2010, 85, pp. 19-32.

[9] American Public Health Association (APHA). Standard methods for the examination of water and wastewater, 20th ed., Washington, DC., 1998.

[10] Jung, Y., Yoon, Y., Kwon, M., et al.. Evaluation of energy consumption for effective seawater electrolysis based on the electrodes and salinity, Desalination and Water Treat., 2015, 57, pp. 10136-10145. 